\title{
IMPLEMENTASI PENGGUNAAN RUANG OVEN UNTUK KELOMPOK PENGRAJIN MEBEL KECAMATAN PEDURUNGAN SEMARANG
}

\author{
Ahmad Fauzan Zakki', Solichin Djazuli Said ${ }^{2}$ \\ ${ }^{1)}$ Departemen Teknik Perkapalan, Fakultas Teknik, Universitas Diponegoro \\ Jl. Prof. Soedarto, SH, Kampus Undip Tembalang, Semarang, Indonesia 50275 \\ 2) Departemen Teknologi Industri, Sekolah Vokasi, Universitas Diponegoro, \\ Jl. Prof. Soedarto, SH, Kampus Undip Tembalang, Semarang, Indonesia 50275 \\ Email: ahmadfzakki@undip.ac.id
}

\begin{abstract}
ABSTRAK
Berdasarkan hasil observasi di lapangan melalui pengamatan langsung dan wawancara terhadap para pengrajin-pengrajin kelompok binaan "aska furniture" dalam UKM "nuriska intergraha", Semarang mengakui adanya beberapa permasalahan yang dihadapi dalam proses produksi mebel yaitu susahnya proses pekerjaan finishing ducco bila dilakukan pada saat musim penghujan, hal ini menyebabkan tertundanya proses produksi mebel. Belum dimilikinya peralatan-peralatan dan sistem instalasi penunjang pekerjaan finishing ducco indoor, seperti ruang pengering/oven dan indoor spray booth merupakan kendala bagi UKM "nuriska intergraha" yang memiliki anggaran belanja kecil dan sangat terbatas. Upaya peningkatan produktivitas melalui pengembangan dan penerapan fasilitas ruangan kamar pengering / oven cat yang membantu proses produksi mebel pada UKM "nuriska intergraha", khususnya untuk mempermudah proses pengeringan cat dan pelapisan dasar (epoxy) pada saat musim penghujan, menjadi fokus penelitian ini.
\end{abstract}

Kata kunci: ruang pengering/oven; musim penghujan; peningkatan produktivitas.

\section{ABSTRACT}

Based on observations in the field through direct observation and interviews with the group of craftsmen "aska furniture" in UKM "nuriska intergraha", it is recognized that the problems in the furniture production process is the difficulties of the process of finishing work during the rainy season. This limitation may caused a delay in the furniture production process. The unavailabity of the facilities and system installation that support indoor painting during the finishing work, such as the drying chamber I oven and indoor spray booth is a significant problem for UKM "nuriska intergraha" which has a small budget and very limited. The focus of this study to improve productivity through the development and implementation of indoor facilities paint booth that helps the process of furniture production in UKM "nuriska intergraha", in particular to facilitate the process of drying paint and coating base (epoxy) during the rainy season,.

Key words: traditional furniture, paint booth, rainy season, improve productivity 


\section{PENDAHULUAN}

UKM "Nuriska intergraha" memulai usahanya pada tahun 2010 berlokasi di Kelurahan Pedurungan, Kecamatan Pedurungan. Mebel yang diproduksi oleh UKM "Nuriska intergraha" lebih dikhususkan untuk menunjang desain interior rumah yang dibuat dan didesain sesuai dengan keinginan pelanggan. Produk-produk yang biasa dihasilkan oleh UKM "nuriska intergraha" adalah kitchen set, lemari pajangan, lemari baju, satu set furniture kamar tidur, satu set furniture ruang keluarga dan sejenisnya.

Proses produksi furniture yang dilakukan oleh UKM "Nuriska intergraha" dimulai dari proses pekerjaan pembuatan kerangka yang kemudian dilanjutkan dengan pekerjaan pembuatan bodi furniture. Pekerjaan pembuatan bodi dilanjutkan hingga proses akhir dengan hasil bentuk furniture. Bodi mebel kemudian dikeringkan kembali dengan dijemur dibawah sinar matahari. Setelah itu dilakukan pengecekan terhadap kualitas bodi mebel dan dilakukan perbaikan bila ditemui kerusakan-kerusakan kecil akibat penyetokan kayu dan sisa lem perekat kayu. Setelah produk bodi sudah sempurna, kemudian dilanjutkan dengan proses anti rayap dan pendempulan.

Proses untuk pemberian anti rayap pada produk furniture secara merata untuk memberikan kewetan dan umur dari kayu dari serangan hama rayap kayu proses memakan waktu +1 hari. Setelah produk/barang dilakukan pemberian anti rayap kemudian barang tersebut dihaluskan dengan mesin amplas dan gerinda, sehingga menjadi lebih halus dan bagus, setelah dirasa cukup, barang mebel tersebut dilapisi dengan wood filler, lalu diamplas kembali hingga wood filler tersebut rata. Pada material plywood, biasanya tidak perlu dilakukan proses pemberian anti rayap, karena plywood sudah mengandung anti rayap yang diberikan oleh produsen plywood.

Tahapan selanjutnya adalah pengamplasan dan pemberian cat dasar (epoxy). Penghalusan permukaan mebel dilakukan dengan menggunakan amplas no. 120 dan dilanjutkan dengan amplas no. 180. Pengamplasan juga dilakukan pada permukaan bodi yang diberi dempul. Proses penutupan pori-pori kayu menggunakan dua macam lapisan. Lapisan pertama adalah cat meni kayu yang berfungsi untuk mematikan serat kayu. Lapisan kedua adalah cat dasar (epoxy), yang dilakukan dengan menggunakan teknik cat semprot, agar cat dapat tersebar secara merata dan tidak meninggalkan bekas goresan. Proses pengeringan cat epoxy biasanya memakan waktu selama 6 jam.

Proses pelapisan cat dasar (epoxy) adalah memberi lapisan pada warna untuk mengikat dan mengeluarkan kecerahan warna cat akhir. Proses ini dilakukan dengan alat bantu kompresor dan spray gun agar lebih rata dan tidak terlalu banyak terjadi overlapping cat.lapisan cat dasar kering sempurna sebelum dihaluskan. Cat dasar dihaluskan dengan amplas no 1000 dengan bantuan air untuk memperoleh permukaan yang licin.

Selanjutnya proses yang dilakukan adalah proses penyemprotan warna. Pada proses penyemprotan warna dibagi menjadi tiga tahapan, yaitu : Penyemprotan warna dasar, penyemprotan warna akhir dan yang terakhir adalah penyemprotan topcoat. Proses penyemprotan warna dilakukan berulang-ulang disetiap sisi secara detail untuk mendapatkan hasil warna baik, warna standar atau warna cerah. Pada warna-warna cerah pengerjaan bisa sampai 3 kali proses. Saat proses pengecatan warna akhir dilakukan, cuaca harus benar-benar kondusif yaitu cukup cahaya dan cukup panas atau 
pada saat matahari sedang naik, dalam hal ini proses pengeringan yang sempurna akan menghasilkan kecerahan warna yang semakin muncul dan kuat.

Tahapan akhir dalam pembuatan mebel yaitu tahap pemasangan engsel pintu, pemasangan kunci, handle tangan dan segala kelengkapan dan pernak-pernik mebel. Selanjutnya dilakukan pengecekan ulang terhadap kondisi produk akhir mebel. Bila sudah dinyatakan sempurna maka proses deliveri dapat dilakukan oleh produsen. Aktivitas produksi mebel di UKM "Nuriska intergraha" dapat dilihat pada Gambar. 1
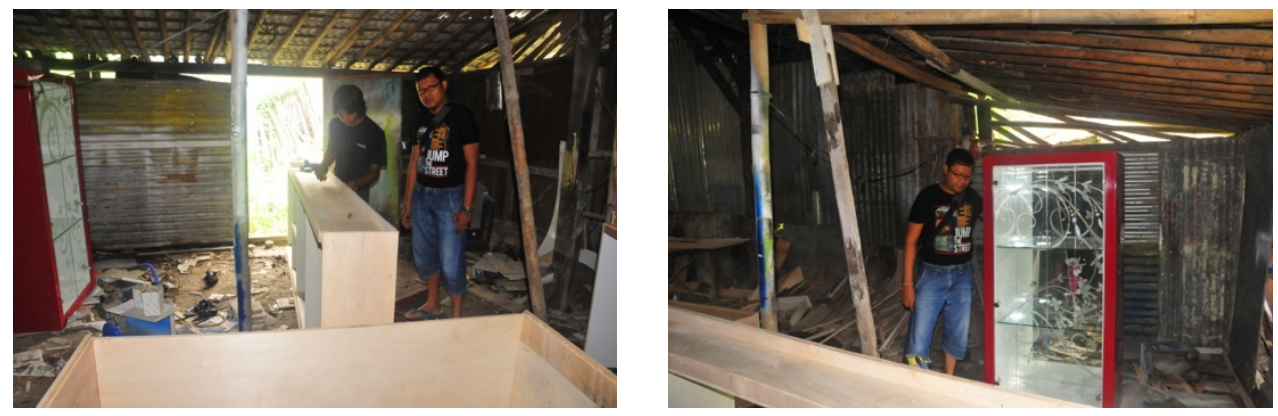

Gambar 1. Aktivitas produksi mebel di UKM "Nuriska Intergraha"

Luaran yang dihasilkan dari penelitian ini adalah berupa produk fasilitas ruangan kamar pengering / oven cat yang membantu proses produksi mebel pada UKM "nuriska intergraha", khususnya mempermudah proses pengeringan cat dan pelapisan dasar (epoxy) pada saat musim penghujan. Secara teoritis ruangan pengering/oven cat adalah sebuah ruangan yang didesain dengan dilengkapi oleh fasilitas untuk mengendalikan besarnya temperatur ruangan untuk mempercepat proses pengeringan pada pekerjaan pengecatan dan pelapisan, [1].

\section{TINJAUAN PUSTAKA}

Furniture/mebel adalah istilah yang digunakan untuk perabot rumah tangga yang berfungsi sebagai tempat penyimpan barang, tempat duduk, tempat tidur, tempat mengerjakan sesuatu dalam bentuk meja atau tempat menaruh barang di permukaannya. Misalnya furniture sebagai tempat penyimpan biasanya dilengkapi dengan pintu, laci dan rak, contoh lemari pakaian, lemari buku dan sejenisnya. Furniture dapat terbuat dari kayu, bambu, logam, plastik dan lain sebagainya. Namun akhir-akhir ini, furniture lebih banyak ditekankan pada unsur desain dan menggunakan material alternatif seperti Finir, Kayu lapis (plywood), Blockboard, Medium Density Fibreboard (MDF), High Density Fibreboard (HDF) dan particle board, (Gambar 2), [2].

Industri mebel telah lama diakui sebagai industri padat karya yang menyerap banyak tenaga kerja. Seiring dengan perkembangan pasar industri mebel kini diarahkan kepada penghasil produk yang bernilai tinggi, berdaya saing global dan berwawasan lingkungan sehingga industri mebel dapat terus konsisten sebagai industri prioritas penghasil devisa negara. Daya saing industri mebel Indonesia terletak pada sumber bahan baku alami yang melimpah, keragaman corak dan desain yang berciri khas lokal serta didukung oleh sumber daya manusia dan teknologi yang memadai. Produk mebel Indonesia memiliki nilai keunggulan pada daya saing dalam diferensiasi maupun harga, 
diferensiasi pada interior dan eksterior mebel masih mengandalkan sentuhan seni ukir dan keragaman jenis kayu dan serat alam sehingga memiliki nilai pada desain unik.

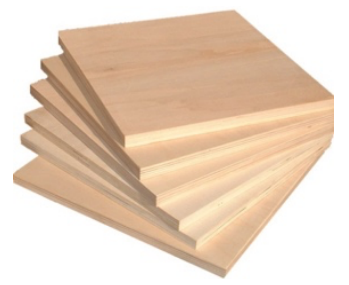

(a)

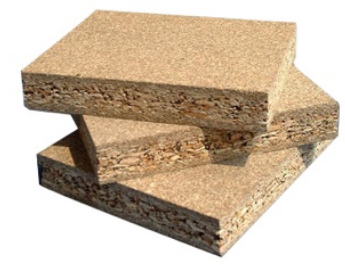

(c)

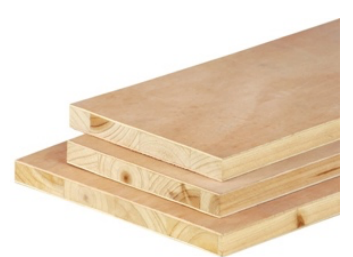

(b)

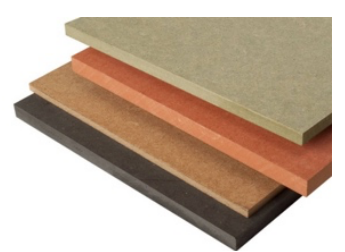

(d)

Gambar 2. Material alternatif untuk mebel: (a) kayu lapis/plywood; (b) blockboard; (c) particle board; (d) high density fibreboard / HDF

Industri mebel di Jawa Tengah memiliki potensi yang cukup tinggi untuk dikembangkan. Selain itu, produksi mebel telah dikenal sejak lama karena kualitas, seni dan harga yang kompetitif. Pusat produsen mebel di Jawa Tengah tersebar di berbagai kota seperti Jepara, Klaten, Sukoharjo, Semarang, Kudus, Rembang, Blora dan Sragen (Kementerian Kehutanan, 2010). Tetapi secara nilai ekspor masih kalah dengan Jawa Timur misalnya Surabaya tiap bulannya bisa 200 - 400 kontainer menyumbang hingga $60 \%$ untuk ekspor nasional US\$ 1,8 miliar. Jawa Tengah baru menyumbang sekitar 40 $\%$, kemudian disusul Jawa Barat, Cirebon dan Tangerang, [3]

UKM "Nuriska intergraha" dan kelompok binaan-nya "Aska furniture" yang menjadi mitra dalam kegiatan ini berada di Desa Rejosari Meteseh dan Desa Karang Lo, Kecamatan Pedurungan, Semarang. UKM "Nuriska intergraha" dalam hal ini sebagai mitra pertama yang sudah memiliki pengalaman dalam memproduksi kerajinan mebel berbahan plywood, sedangkan mitra kedua adalah Kelompok Binaan dari UKM "Nuriska intergraha" yaitu "Aska furniture" yang beranggota para pengrajin mebel dan furniture.

\section{BAHAN DAN METODE}

Cat Oven sebenarnya adalah sebuah sistem pengecatan menggunakan Oven / Paint booth, sebuah ruang pengecatan yang tertutup yang digunakan untuk mengecat, bukan jenis cat nya. Fungsi Oven/ Paint booth dalam pengecatan sangat krusial. Oven dibutuhkan untuk hasil pengecatan yang bebas debu, kotoran dan segala cuaca, sehingga menghemat waktu pengerjaan. Garis besar dari sistem Oven sendiri adalah: airflow (perputaran udara) dan kebersihan. Jika airflow lancar, uap dari sisa cat yang tidak menempel bisa langsung terbuang dan tidak menempel / jatuh lagi. Selain itu, jika airflow lancar, kinerja painter (tukang cat) juga akan maksimal, karena uap cat dan clear yang pekat bisa segera terbuang, (lihat Gambar 3). 


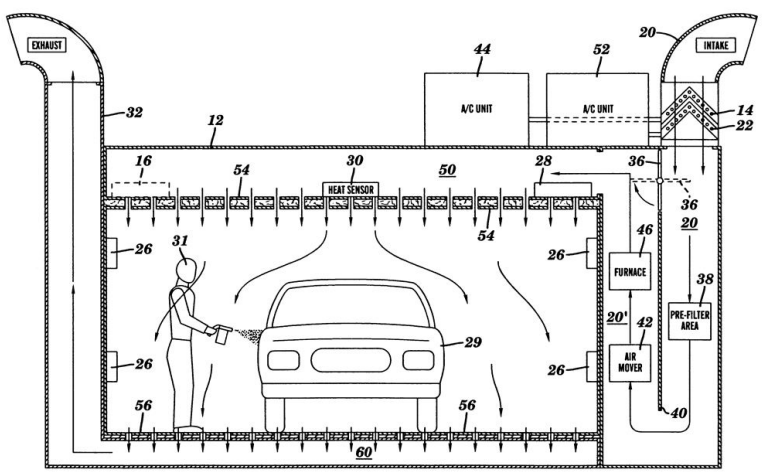

Gambar 3. Instalasi sistem ruang pengering, [4]

Bagian penting kedua adalah kebersihan, airflow akan percuma jika yang tersedot adalah udara kotor (mengandung debu), karena akan menempel di permukaan yang dicat dan merusak hasil keseluruhan. Oleh karena nya, sebuah oven yang bagus adalah yang mampu menyediakan aliran udara bersih. Oven yang sempurna adalah oven yang juga mampu memberikan pemanasan pada suhu tertentu untuk proses pengeringan cat.

Istilah Oven sendiri muncul karena di Paint Booth profesional menyediakan juga elemen pemanas baik heater maupun infra red thermal lamp (lampu Infra Merah) yang bisa memanaskan suhu ruangan sampai dengan 60 derajat Celcius. Harga Paint booth profesional ini sangat mahal, sehingga tidak banyak bengkel yang memakainya. Sebagai alternatif, banyak bengkel yang membuat paint booth custom. Di paint booth custom ini, prinsipnya sama yaitu airflow yang bersih, tetapi biasanya tidak menggunakan heater maupun lampu Infra Red karena investasinya yang mahal. Sebagai pengganti heater, digunakan lampu sorot / lampu tembak berdaya $300 \mathrm{~W}$ sebanyak $6-8$ buah per booth. Lampu sebanyak ini jika efektif, akan dapat menghasilkan panas hingga 40 derajat celcius, [5].

Upaya peningkatan produktivitas melalui pengembangan ruang pengereing/ oven pada UKM "Nuriska intergraha", menjadi fokus usulan kegiatan penelitian ini. Perancangan desain ruang pengering/oven cat akan dicapai melalui beberapa target-target luaran yang terdiri dari:

- Alat prototipe ruang pengering/oven cat sederhana dan terjangkau yang mampu membantu proses pengeringan pada finishing ducco, khususnya pada saat musim penghujan.

- Peningkatan produktivitas melalui penerapan ruang oven cat yang diusulkan dapat dicapai dengan cara menghemat waktu produksi dan peningkatan kemampuan proses finishing ducco di ruang indoor, sehingga tidak terpengaruh cuaca .

- Fasilitas ruang pengering/oven cat yang diusulkan juga mempertimbangkan faktorfaktor keselamatan kerja, kesehatan dan kenyaman kerja sehingga penggunaan fasilitas dapat dilaksanakan dengan baik dan nyaman.

- Diperoleh program-program peningkatan produktivitas bagi UKM dan pengrajin mebel di Semarang, sehingga keberlanjutan dan daya saing produk furniture meningkat.

- Diperoleh suatu analisis sistem manufaktur pada proses produksi mebel furniture dari plywood, sehingga dapat membantu merencanakan strategi pengembangan bisnis furniture. 
- Diperoleh pemahaman pada pengrajin dan pemilik usaha pembuatan mebel, tentang penggunaan dan manfaat perancangan, dan penerapan fasilitas ruang pengering/oven cat bagi perkembangan usaha produksi mebel skala kecil dan menengah.

Metode penelitian yang digunakan pada program ini diawali dengan melakukan evaluasi terhadap proses produksi pada UKM "Nuriska Intergraha". Berdasarkan dari hasil survei awal tersebut, kemudian ditentukan tahapan-tahapan pelaksanaan kegiatan pengabdian masyarakat ini. Tahapan-tahapan pelaksanaan kegiatan tersebut dinyatakan dalam diagram alir yang dapat dilihat pada Gambar 4.

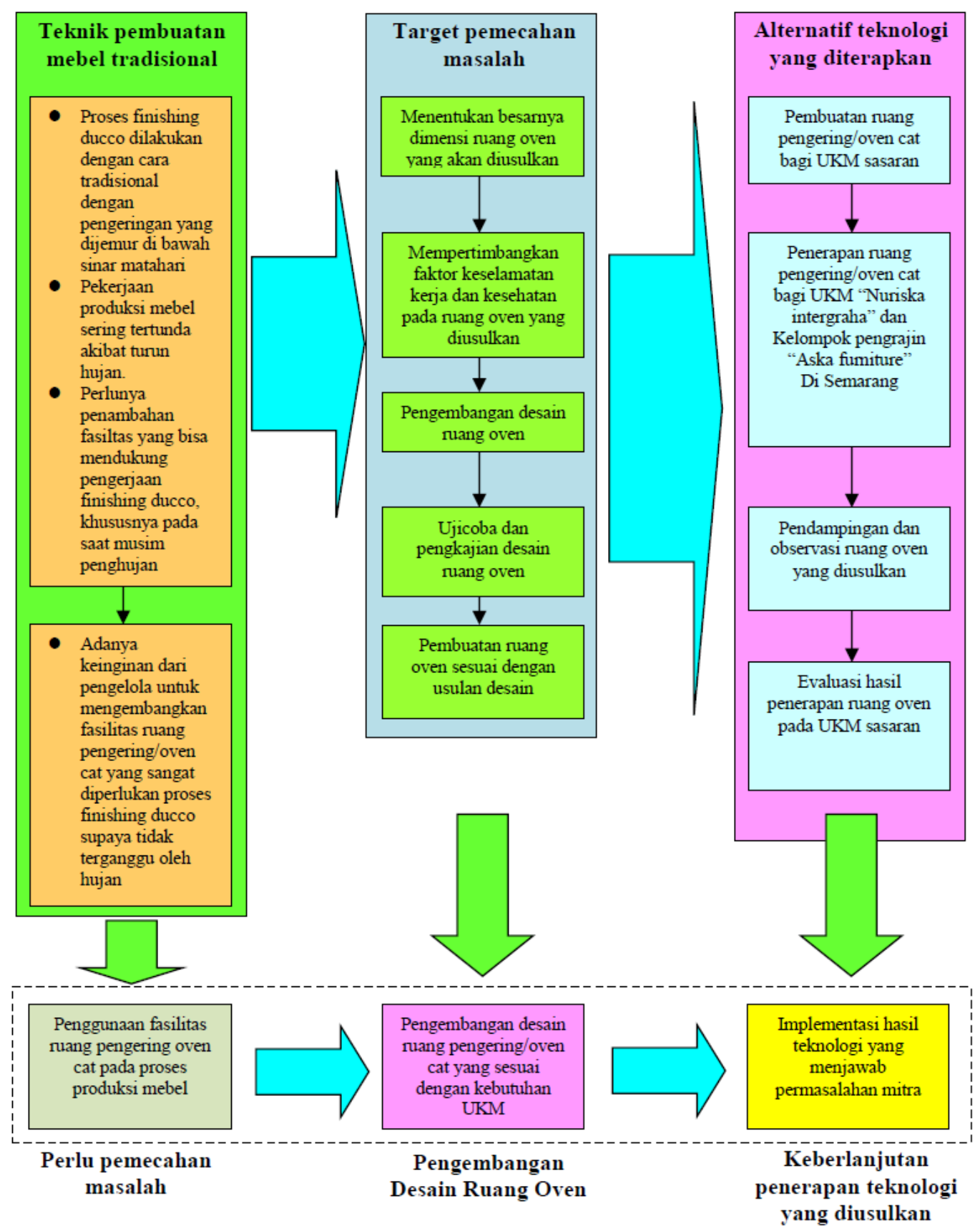

Gambar 4. Diagram alir metode pelaksanaan kegiatan penelitian 


\section{HASIL DAN PEMBAHASAN}

\section{Desain ruang oven dan spray booth untuk para pengrajin mebel}

Pada tahapan ini telah dikembangkan ruang oven dan spray booth para pengrajin mebel. Desain ruang oven dan spray booth disesuaikan dengan kebutuhan dan kemampuan mebel dalam mengoperasikan alat. Selain berdasarkan pengaturan suhu dan tingkat kekeringan ruang oven dan spray booth juga dilengkapi dengan alat sirkulasi udara (airflow) dan komponen pengecatan. Desain ruang oven dan spray booth memiliki kelebihan yaitu ducco yang dicat atau dikerjakan di dalam ruang oven tidak terkena debu atau kotoran dari luar, sehingga menghasilkan produk mebel yang berkualitas.

\section{Pembuatan ruang oven dan spray booth}

Desain yang telah dikembangkan selanjutnya dilakukan pembuatan. Pada proses pembuatan ruang oven dan spray booth dilakukan oleh tenaga-tenaga terlatih dan terampil sehingga produk yang dihasilkan benar-benar sesuai dengan desain yang telah dikembangkan dapat dilihat pada Gambar 5
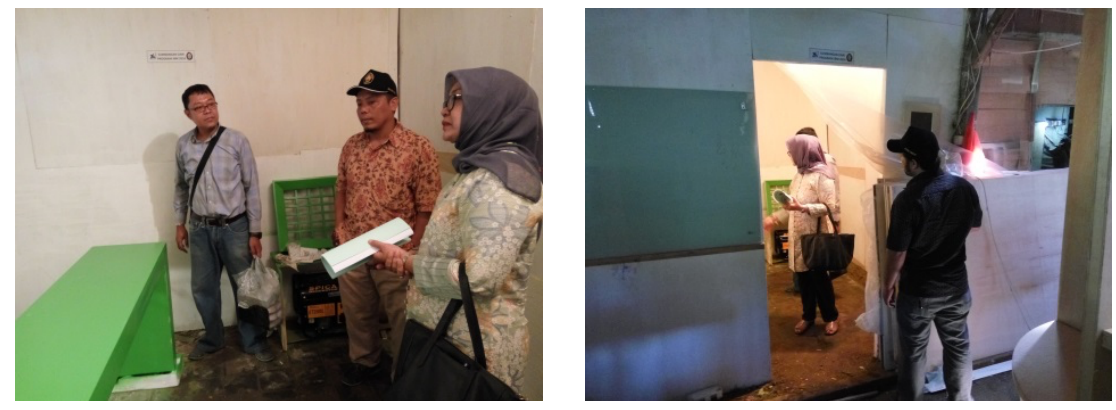

Gambar 5. Desain ruang oven mebel yang dikembangkan

\section{Finishing ruang oven dan spray booth}

Pada tahap berikutnya akan dilanjutkan perakitan pada dinding ruang oven, pemasangan lampu heater dan pemasangan alat sirkulasi udara (airflow). Proses finishing akan dilakukan penempatan alat cat, kompresor, dan pemasangan instalasi listrik untuk menghidupkan airflow dan lampu heater. Proses ini dilakukan agar produk yang dihasilkan memenuhi kualitas yang diharapkan oleh pengguna produk yaitu para pengrajin mebel. Selain mempercantik produk, proses finishing juga membantu melindungi produk agar lebih awet dan tahan lama.

\section{Penerapan produk yang telah dikembangkan pada UKM mitra}

Produk ruang oven selanjutnya diberikan kepada mitra UKM agar digunakan oleh para pengrajin mebel di tempat kerjanya. Pendampingan pada penerapan produk dilakukan agar produk yang dihasilkan sesuai dengan prosedur penggunaan produk. Selain itu pada proses pendampingan juga dilakukan umpan balik dari pengguna produk untuk perbaikan dan masukan bagi perancang produk.

Berdasarkan pengamatan dan hasil wawancara yang dilakukan oleh tim pengabdian, ruang oven yang dikembangkan untuk perbaikan sistem produksi mebel telah menunjukkan hasil perubahan yang baik, lihat Tabel 1. Para pengrajin mebel merasa bahwa dengan ruang oven baru ini dapat menerima order mebel ducco meskipun pada musim penghujan sehingga pendapat pengrajin semakin lebih baik 
Tabel 1. Perubahan akibat penerapan alat polishing

\begin{tabular}{|c|c|c|c|}
\hline No & Uraian & Sebelum diaplikasikan & Sesudah diaplikasikan \\
\hline 1 & $\begin{array}{l}\text { Waktu yang } \\
\text { dihabiskan untuk } \\
\text { proses finishing ducco }\end{array}$ & 1 minggu & Kurang dari 3 hari \\
\hline 2 & $\begin{array}{l}\text { Jumlah mebel yang } \\
\text { dihasilkan di musim } \\
\text { penghujan }\end{array}$ & 4 Unit per Bulan & 15 Unit per Bulan \\
\hline 3 & $\begin{array}{l}\text { Jumlah keluhan } \\
\text { tertundanya kerja } \\
\text { akibat turun hujan }\end{array}$ & Semua pekerja & Tidak ada \\
\hline
\end{tabular}

\section{KESIMPULAN}

Kegiatan implementasi penggunaan ruang oven untuk kelompok pengrajin mebel kecamatan pedurungan Semarang dalam upaya peningkatan produktivitas di musim penghujan telah dilaksanakan. pengembangan desain ruang oven telah dikembangkan dan diaplikasikan pada mitra. Hasil menunjukkan bahwa ruang oven telah memberikan peningkatan produktivitas khususnya pada proses produksi mebel ducco di musin penghujan. Peningkatan kemampuan dalam proses pengeringan cat ducco yang ditawarkan mampu memperbaiki proses produksi mebel serta mengurangi keluhan rendahnya kualitas pengeringan cat ducco khususnya pada musim penghujan. Peningkatan produktivitas dan peningkatan kualitas dapat dicapai dengan proses pengeringan dalam ruang oven di tempat mitra

\section{DAFTAR PUSTAKA}

[1] Jeff Jewitt, 2007. "Make a Simple Spray Booth, Inexpensive foldaway booth lets you safely spray indoors". Diakses dari situs fine wood working. (http://www.finewoodworking.com/how-to/article/make-a-simple-spraybooth.aspx) diakses pada tanggal 29 Maret 2015

[2] Atfestoro, 2010. "Pengetahuan Bahan Furniture". Diakses dari situs Atfestoro (https://atfestoro.wordpress.com/2010/11/19/pengetahuan-bahan-furniture/) diakses pada tanggal 29 maret 2015.

[3] Ayudea, Fani.2013. "Pelaku Industri Mebel Optimistis Ekspor Tembus 3 Miliar Dolar AS". Diakses pada tanggal 2 Oktober 2013 dari (http://m.suaramerdeka.com/index.php/read/news/2013/11/25/180945)

[4] Laris abadi, 2012. "Apa itu Cat Oven", diakses dari situs Laris Abadi (http://larisabadi.com/2012/11/23/apa-itu-cat-oven/). Diakses padatanggal 29 Maret 2015

[5] Wisno Furniture Finishing, 2011. "Lebih lanjut tentang finishing kayu". Diakses dari situs semua tentang kayu (http:/www.tentangkayu.com/2010/01/lebih-lanjuttentang-finishing-kayu.html) diakses pada tanggal 29 Maret 2015 